\title{
Skin Vascular Disorder
}

National Cancer Institute

\section{Source}

National Cancer Institute. Skin Vascular Disorder. NCI Thesaurus. Code C35254.

A disorder of the vasculature of the skin. 